\title{
OVERVIEW OF HEAT PIPE STUDIES DURING THE PERIOD 2010-2015
}

\author{
Stéphane Lips ${ }^{\mathrm{a}, 1,}$ Valérie Sartre ${ }^{\mathrm{a}}$, Frédéric Lefèvre ${ }^{\mathrm{a}}$, Sameer Khandekar ${ }^{\mathrm{b}}$, Jocelyn Bonjour ${ }^{\mathrm{a}}$ \\ ${ }^{a}$ CETHIL UMR5008, Université de Lyon, CNRS, INSA-Lyon, F-69621, Villeurbanne, France \\ ${ }^{b}$ Department of Mechanical Engineering, Indian Institute of Technology Kanpur, Kanpur 208016, India
}

\begin{abstract}
Despite the numerous studies on heat pipes over the last fifty years, the development of predictive tools for the design of heat pipes remains challenging, even for conventional technologies. As a result, heat pipes are still the object of more than 250 scientific articles a year. The present review aims to identify and understand the current scientific approaches followed by scientists in heat pipe science. The different types of heat pipe are reviewed in order to identify the main phenomena involved in these systems. A brief overview of the heat pipe history is given and the different applications are presented. A global review of the recent studies on heat pipes is then presented. Advances are identified in terms of heat pipe characterisation, scientific issues linked to the working fluid, understanding of phase-change heat transfer in thin liquid films and system modelling. Examples of recent works are detailed to highlight the strategies that can be followed to answer the current issues. This global review enables to highlight the main advances on heat pipe science of the last five years and to draw perspectives on the forthcoming scientific results.
\end{abstract}

\section{INTRODUCTION}

Heat pipes are widely used in many industrial applications. They enable the transfer of high heat fluxes with low temperature gradients by using the latent heat of vaporisation of a working fluid. The diversity of the different kinds of heat pipes reflects the diversity of the conditions in which they are used. However, whatever the type of heat pipe, their normal behaviour is bounded by several operating limits that depend on various phenomena. Heat pipes are the object of thousands of scientific articles published in more than a hundred international journals. Two long-term established series of international conferences are dedicated to them every two to three years and they are present at all general conferences dedicated to heat transfer. However, despite the numerous studies on heat pipes for fifty years, the development of predictive tools for their design is still challenging, even for conventional technologies. It results in a real limitation in the spreading of heat pipes in the industry, as each new heat pipe has to be carefully designed for each specific application. By means of a review of the recent works published on heat pipes, the authors aim to understand the scientific key issues

\footnotetext{
${ }^{1}$ Corresponding author.Email: stephane.lips@insa-lyon.fr
} 
leading to this situation and the strategies that can be implemented to progress towards a better understanding of the different types of heat pipes.

In 2007, Riffat and Ma proposed a review of developments in heat pipe technology and applications between 2000 and 2005. They noted different kinds of advances during the period. New kinds of wick structures for conventional and flat heat pipes were proposed and new working fluids were incorporated. They highlighted the development of new types of loop heat pipes (LHP and CPL) that were expected to be widely used in industrial applications. They also noted studies on flexible heat pipes as well as on micro heat pipes. New applications were studied as solar collector systems and heat pipe integrated turbines. Traditional topics as high temperature heat pipes and space applications were also reported. For air conditioning systems, the coupling between phase-change materials and heat pipes was investigated. Lastly, they reported the development of new models and mathematical methods for the design of various kinds of heat pipes.

Ten years later, the research field on heat pipes has changed substantially. Figure 1 presents a word cloud realised from the titles of the articles published on heat pipes between 2012 and 2014 (about 800 papers). In this word cloud, the size of the words is proportional to the square root of the number of occurrence of each word. It is a convenient tool to have a general overview of a given field (McNaught \& Lam, 2010). Beside the words directly related to the heat pipes themselves and their main components, it appears that experimental works are dominant compared to simulations, numerical analyses and modelling. On the other side, analytical approaches are very rare. Papers are often interested in heat pipe performance and the diversity of the applications appears, even in the paper titles (electronic cooling, LED, air conditioning, solar collector, cryogenic applications, vehicles, thermoelectric generators, energy storage...). One can note the importance of the working fluid (water, ethanol, mixture) and materials (metal, copper, silicon, aluminium, glass, ceramic, copper oxide $(\mathrm{CuO}))$ used in heat pipes, as they explicitly appear in many paper titles. The link between heat pipe science and material science is highlighted by the important occurrence of the words "nanofluid(s)" and "carbon nanotubes", but also by the words "material", "sintered wick" and "process of fabrication". Progress in manufacturing also promotes the development of micro heat pipes as well as of light weight heat pipes.

This word cloud also gives a brief summary of the subject of the studies: effect of gravity forces and inclination angles are studied, as well as magnetic and electric fields. The start-up procedure is the topic of several articles and the transient response of heat pipes is studied. The word cloud even gives clues on some experimental devices used to characterise heat pipes, such as neutron radiography. 


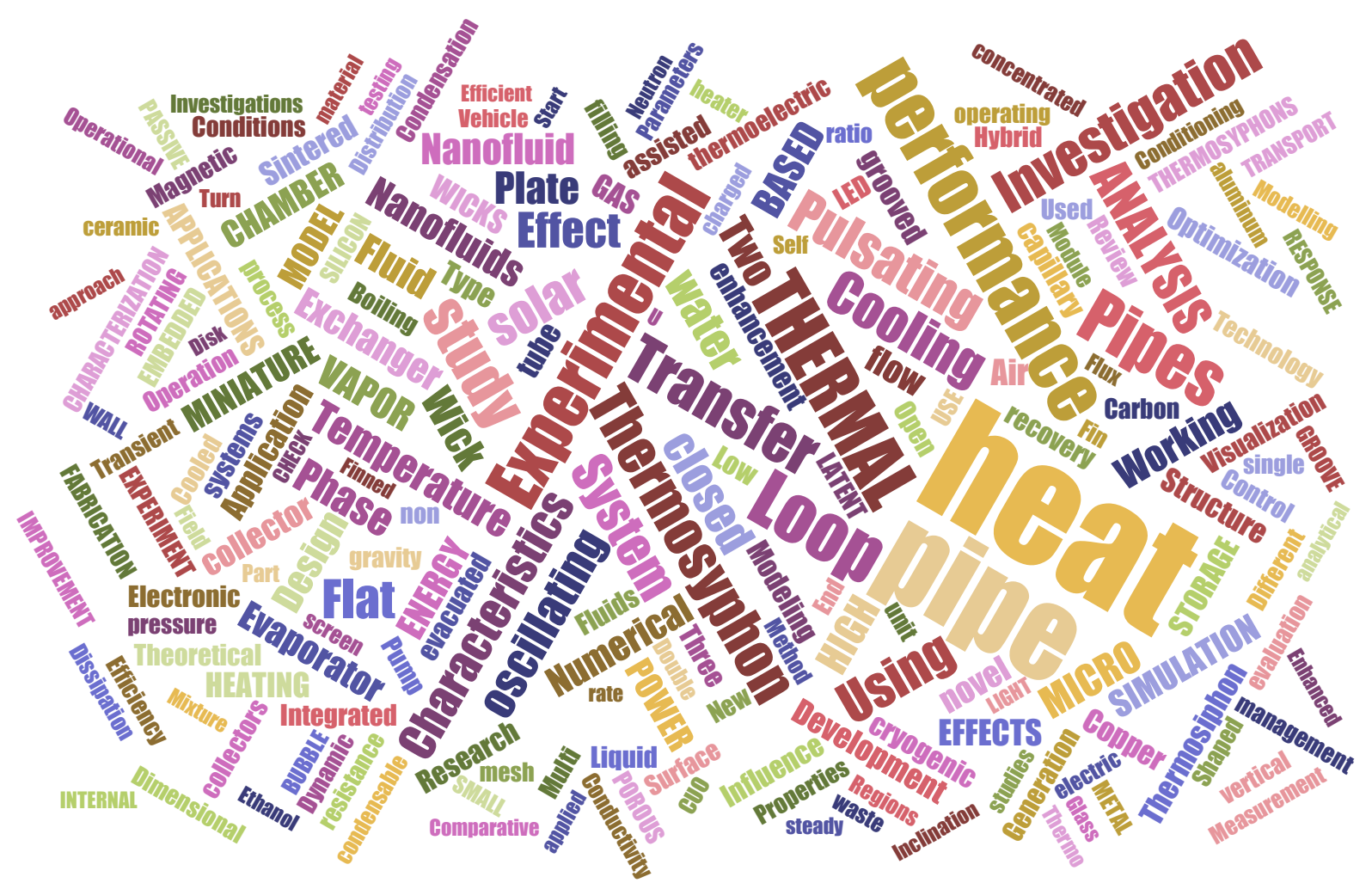

Figure 1 Word cloud of the titles of heat pipe articles published between 2012 and 2014 (200 top used words of about 800 papers)

The diversity of the words present in the titles is also a reflection of the diversity of the journals in which the papers were published. The 800 papers dedicated to heat pipes between 2012 and 2014 were published in more than 200 different international journals. Figure 2 presents the distribution of the papers in the main journals. Despites the great number of journals publishing articles on heat pipes, about $40 \%$ of the papers was published in only 10 journals and almost all of them are dedicated to research on heat transfer. However, one can see that the heat pipes also interest the communities of solar and renewable energy applications, industrial applications and electronic cooling applications.

If the word cloud and the typology of the international journals publishing studies on heat pipes enable to highlight the main keywords describing the current research on heat pipes, it does not give information on the content of the articles.

The present review article aims to draw a summary of the research dedicated to heat pipes during the period 2010-2015. Its goal is not to be exhaustive, nor to discuss the different scientific results, but is rather to give an overview of the various approaches used by the current heat pipe research community. In a first part, the various types of heat pipes are reviewed in order to identify the main phenomena involved in these systems. Then, as knowing the past is useful to understand the present, a brief history and an overview of the applications are presented. The recent advances are finally detailed and classified in terms of system characterisation, scientific issues involving the working fluid, phase-change heat transfer in thin films and heat pipe modelling. 


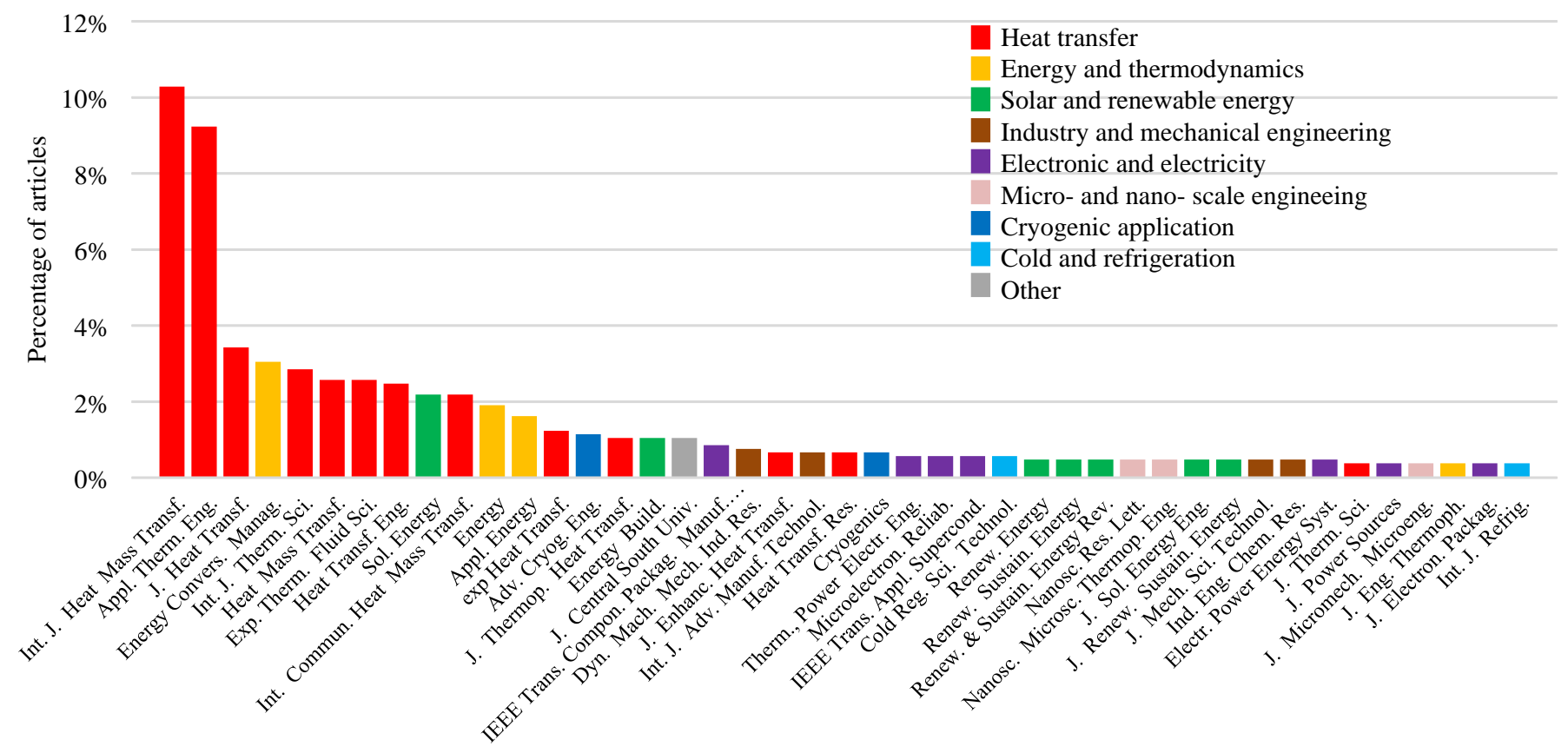

Figure 2 Distribution of the recent papers (2012-2014) on heat pipes in the various international journals

\section{BRIEF OVERVIEW OF THE HEAT PIPE TECHNOLOGIES, HISTORY AND APPLICATIONS}

\subsection{The various heat pipe technologies}

A heat pipe is a system which is able to transfer high heat fluxes from a heat source to a heat sink with a low thermal resistance using liquid-vapour phase change (Reay et al., 2013). It consists of a cavity filled by a fluid at saturation. The liquid evaporates at the contact of the heat source and condenses close to the heat sink. The way the vapour and the liquid flow to the condenser and to the evaporator respectively depends on the type of heat pipe. The main types of heat pipes are summarised in figure 3. The distinction can be made between conventional heat pipes, loop heat pipes and oscillating heat pipes.

The family of conventional heat pipes comprises thermosyphons, cylindrical heat pipes, flat plate heat pipes and rotating heat pipes. The liquid and vapour flows are countercurrent within the heat pipe body. The liquid flows from the condenser to the evaporator owing to either gravity, capillary, centrifugal forces or a combination of these forces. In capillary heat pipes, the capillary structure (grooves, meshes or porous medium) has to be continuous from the condenser to the evaporator.

The generic term 'loop heat pipes' refers to loop heat pipes themselves (LHPs), but also capillary pumped loops (CPLs) and two-phase loop thermosyphons (also called closed-loop thermosyphons). In these systems, the liquid and vapour flow in separate lines. For LHPs and CPLs, the sum of frictional and gravitational pressure drops are compensated by the capillary forces in the capillary structure placed at the evaporator only. A CPL differs from a LHP by the place of the reservoir, which has a great importance on the overall system behaviour. In closed-loop thermosyphons, the gravitational forces compensate for the frictional pressure drop. 


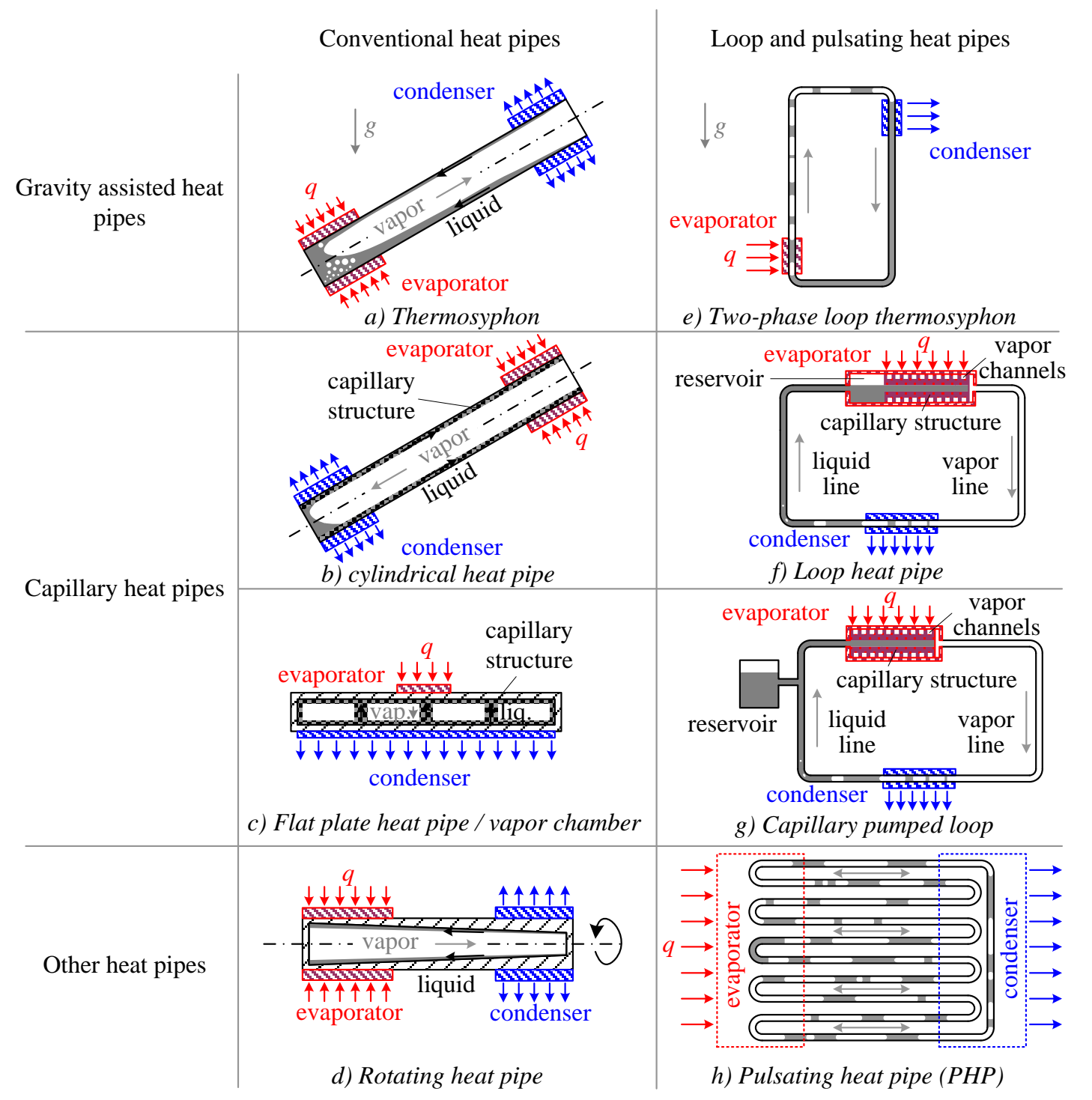

Figure 3 Different heat pipe technologies

The oscillating heat pipes, also called pulsating heat pipes (PHPs) are made of a single meandering tube placed between the heat source and the heat sink. Its diameter, close to the fluid capillary length, leads to a distribution of the fluid within the tube into liquid plugs and vapour slugs. The violent vaporisation of multiple liquid slugs in the evaporator, associated to the condensation of multiple vapour plugs at the condenser, generates self-sustained oscillations of the fluid. It leads to an efficient heat transfer from the heat source to the heat sink, both by latent and sensible heat. These systems are cheap and easy to manufacture, but their behaviour is difficult to predict and they are currently sparsely used in the industry.

Despite the strong differences between the various heat pipe technologies, there are several phenomena shared by these systems. Obviously, liquid-vapour phase-change heat transfer is present in all heat pipes. The phase change occurs at the scale of the capillary structure or at the scale of the thin liquid films present in the system. The capillary forces are indeed almost never negligible. Moreover, as the fluid is always heated through a wall, the interactions between the working fluid and the wall, mainly wetting effects, are of great importance. 
Lastly, there is always a coupling between hydrodynamic and thermal phenomena, as the working fluid follows a thermodynamic cycle in the systems.

In the following of the document, research works on heat pipes are classified according to the type of studies and not to the type of systems. The similarity of the phenomena involved in all heat pipes induces that the progress in understanding of one kind of heat pipe generally helps to progress on the other kinds.

\subsection{History and applications}

In order to have an overview of the research in heat pipe science, a global analysis of the studies published on heat pipes is realised. Figure 4 presents the evolution of the number of articles related to heat pipes indexed on the Web of ScienceTM database between 1975 and 2014.

Table 1 summarises the exact query used to plot figure 4. Several technologies are distinguished by filtering the content on the article title only, so the present analysis does not pretend to be exhaustive, but rather aims to give the general trends of research in heat pipes during the last forty years. The category "others" in figure 4 refers to all papers for which the type of heat pipe has not been identified through the title. They often refer to conventional cylindrical heat pipes, but also to studies dedicated to phenomena involved in heat pipes, in general.

The heat pipe science began during the sixties and conventional heat pipes were soon widely used in space applications, for instance to transfer the heat dissipated by the components to the radiators. To try to reduce the weight of the systems, CPLs and LHPs were invented by the NASA during the sixties and by the Russian Federal Space Agency during the seventies, respectively. However, these technologies were not reliable enough during this period.

During the eighties, terrestrial applications of heat pipes were developed, mainly with thermosyphons because of the difficulty overcoming the gravity forces. Thermosyphons have been widely used in industrial applications, as well as in the heat exchangers. The development of electric locomotives also motivated the use of heat pipes in mobile applications.

During the nineties, new types of heat pipes were invented and more and more studied. Micro heat pipes appeared thanks to the progress of micro technologies. They aimed to reduce the thermal contact resistance between the electronic component and the heat sink by directly integrating the heat pipe into the silicon substrate of the electronic component. At the same time, the progresses in porous material technologies enabled the implementation of CPLs and LHPs in spacecrafts.

Since 2000, the number of papers dedicated to heat pipes increases continuously and reaches now about 250 papers per year. According to Larsen and von Ins (2010), the general annual growth rate of scientific publications is close to $5 \%$, which implies a doubling time of about 15 years. With a doubling time of about 8 years, the growth rate of publications dedicated to heat pipes is much higher than the growth rate of all scientific 
publications. This enhanced research effort is mainly motivated by the increase of the heat flux density dissipated by electronic components, which creates a need for efficient and reliable cooling systems. Heat pipes, especially CPLs and LHPs, are thus developed for terrestrial applications and the systems need to be optimised and perfectly understood in order to deal with gravitational forces and acceleration forces for on-board vehicle applications. At the same time, rising energy prices favor the use of heat pipes in numerous applications, either as a passive system to remove heat, to improve the efficiency of heat recovery systems, or to homogenise the temperature of various systems. In parallel, the continuous progress in new materials and manufacturing processes enables the spreading of heat pipes in many other industrial applications.

In figure 4, one can note the important development of research on CPLs / LHPs over the last 15 years and on PHPs over the last 10 years. Together, they represent currently one third of the papers devoted to heat pipes. The development of reliable LHP would open the use of heat pipes in many applications, as they enable to transfer heat over a longer distance than other types of heat pipes, while having a low sensitivity to gravitational and acceleration forces. The development of PHPs is mainly motivated by the low cost of these kinds of systems. One can also note the remaining importance of research on thermosyphons, despite the age of the early research on this field. These systems are more and more optimised and studies are aimed to push back their operating limits, especially in terms of heat power, heat flux density and operating temperature.

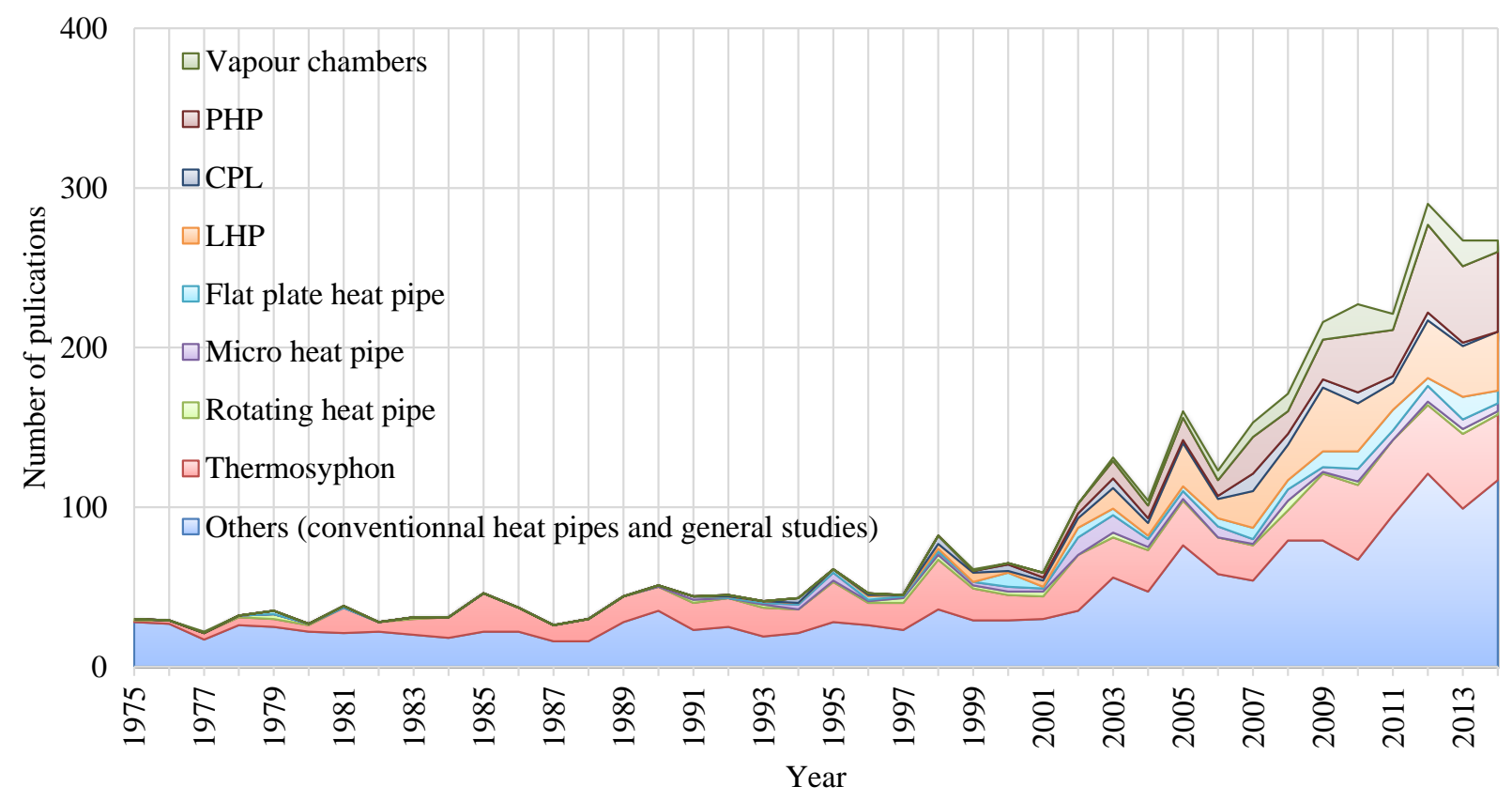

Figure 4 Number of papers dedicated to heat pipes according to the database of Web of Science ${ }^{\mathrm{TM}}$ 
Table 1 Queries corresponding to Figure 4

\begin{tabular}{|c|c|c|}
\hline Type of heat pipe & Query (in title) & $\begin{array}{c}\text { Total } \\
\text { results }\end{array}$ \\
\hline $\begin{array}{c}\text { All kinds of heat } \\
\text { pipes }\end{array}$ & $\begin{array}{r}\text { "heat pipe(s)" or thermosyphon(s) or thermosiphon(s) or "vapo(u)r } \\
\text { chamber(s)" or "capillary pumped loop(s)" }\end{array}$ & 3634 \\
\hline Thermosyphon" & thermosyphon(s) or thermosiphon(s) & 820 \\
\hline Rotating heat pipe & rotating and "heat pipe(s)" & 49 \\
\hline Micro heat pipe & "micro heat pipe(s)" & 112 \\
\hline Flat heat pipe & "Flat (plate) heat pipe(s)" & 119 \\
\hline LHP & "loop heat pipe(s)" & 325 \\
\hline CPL & "capillary pumped loop(s)" & 75 \\
\hline PHP & (pulsating or oscillating) and "heat pipe(s)" & 334 \\
\hline Vapour chambers & "vapo(u)r chamber(s)" & 117 \\
\hline
\end{tabular}

"the term "thermosyphon" can also refer to "single-phase thermosyphons". A rapid analysis of the abstracts shows that single-phase thermosyphons represent between 15 and $20 \%$ of the papers mentioning the term "thermosyphons" in their title.

Scientific issues involved in heat pipes are usually classified in four categories: evaporation heat transfer, condensation heat transfer, flow patterns in heat pipes and capillary flows. In the present article, another classification of the studies available in the literature over the period 2010-2015 was selected:

- The research motivated by the heat pipe characterisation,

- The scientific issues linked to the working fluid behaviour,

- The studies aiming to predict the phase change heat transfer in thin films,

- The development of new heat pipe models.

This classification enables to highlight not only the different scientific issues but also the different scientific approaches that are used by the research teams working on heat pipes. Indeed, the present paper is rather dedicated to the different approaches and current ways to progress on the heat pipe understanding than directly to the scientific results themselves.

\section{RESEARCH MOTIVATED BY THE HEAT PIPE CHARACTERISATION}

\subsection{Determination of the heat pipe performance}

From an industrial point of view, an important outcome of heat pipe studies is the determination of the overall performance of the various heat pipes. The performance can be typically expressed in terms of system thermal resistance and of system capacity to function in given operating conditions (imposed heat flux, ambient temperature, acceleration, orientation...). Many studies are thus devoted to the determination of the heat pipe performance and the numerous prototypes that are tested enable to build important databases for each type of heat pipes. The thermal resistance of a heat pipe usually depends on the heat transfer at the evaporator and at the condenser and thus on many parameters as the working fluid, the fluid fill charge and the effective thermal conductivity of the wick (when exists), but also on other phenomena as the operating regime, or the partial or 
total dry-out of the evaporator. For instance, the thermal performance of LHPs is often characterised by their operating curve (vapour or reservoir temperature as a function of the heat power) and not by their thermal resistance. Determining a heat pipe performance also leads to determine its operating limits, often detected by a sudden increase of the thermal resistance or of the operating temperature. If the different limits are well known from decades, it is not so trivial to link the observed heat pipe behavior to a particular limit.

As an example, Maydanik et al. (2014) recently proposed a review on the performance of loop heat pipes with flat evaporators. The performance of the various geometries is compared, as well as the impact of the working fluid and the materials. Recommendations were then proposed in order to achieve a good performance when designing the evaporator of a LHP. For instance, they advised to use a copper/water combination for the wick material and the working fluid for the temperature range $70-100^{\circ} \mathrm{C}$. For lower temperatures, ammonia can be used but with a compatible material only. They also concluded that LHPs are mainly interesting when the distance between the heat source and the heat sink exceeds $200 \mathrm{~mm}$ and when a loop thermosyphon cannot be used. This kind of review is very important for the community as it enables to summarise the data scattering in a large number of articles.

The review articles that deal with heat pipe performance can also focus on a specific application instead of a specific type of heat pipe. For instance, Srimuang and Amatachaya (2012) proposed a review on heat pipe heat exchangers presented in the literature. Their effectiveness ranged from 0.16 to 0.825 and the authors concluded that the four main influent parameters were the inlet temperature in the evaporator section, the hot and cold air velocities, the fins geometry and the working fluid inside the heat pipe. This example highlights the fact that the main parameters strongly depend on the application in which the heat pipe is used and not only on the type of heat pipe itself.

Moreover, the performance of a heat pipe is not only limited to its thermal performance. For instance, Zhang et al. (2014a) studied the socio-economic performance of a solar water heating system that includes a heat pump and a new type of two-phase loop thermosyphon. They highlighted the fact that three factors have to be prioritised: the energy efficiency, the economic revenue and the environmental benefit. They concluded that the performance of their novel loop thermosyphon, compared to traditional ones, depends strongly on the selected criterion and on the location of the system (London, Shanghai or Hong-Kong in their study). This example shows that reducing the heat pipe performance to its only thermal resistance minimises the challenges that have to face the heat pipe scientific community.

Besides academic papers, many patents are filed, in which specific geometries and configurations are proposed. Patents can deal with specific parts of heat pipe, as condensers (Fried et al., 2013) or wicks (Asfia et al., 2014). Additional parts are also proposed, as a reservoir filled with adsorbent material in order to deal with freezing problems (Bonjour et al., 2013). The large number of patents filed each year shows the strong links between the academic research on heat pipes and their industrial applications. 
In a general way, each time a new heat pipe design is proposed, the first step in studying a prototype is to determine its performance. As an example, Lachassagne et al. (2012, 2013) proposed a new kind of LHP, called CPLIP (Capillary Pumped Loop for Integrated Power), with a reservoir located above the evaporator. In their first paper they determined its performance, and subsequently proposed a model in steady-state conditions. Heat pipes also have to be tested in various operating conditions. For instance, Mameli et al. (2014) characterised a closed loop pulsating heat pipe in microgravity conditions. They showed that their heat pipe is more affected by the variation of the gravity than by the level of gravity itself. They also concluded that the performance of their heat pipe is similar in microgravity and placed horizontally in normal gravity conditions. This kind of conclusion is important for the community to limit the number of tests required in microgravity, as they are expensive and difficult to perform.

Eventually, the last step, after a prototype characterisation, is to study its behaviour in the real system. Studies can be found, for instance, for solar applications (Zhang et al., 2014b), HVAC applications (Zhenying Wang et al., 2015) or electronic cooling applications (Kim \& Kim, 2014). Most of the time, this kind of study focuses on the transient behaviour of the systems and the authors often compare their measurements with the results of transient numerical models. Indeed, the scientific goals of these studies are often to check the relevance of the models that are developed to predict the heat pipe performance for each specific application.

\subsection{Capillary structure characterisation}

For capillary heat pipes, the development of models requires the knowledge of the properties of their capillary structure filled with the working fluids as they have a direct effect on the heat pipe performance. Consequently, the capillary structures are the object of great attention in heat pipe science. New ways of manufacturing new capillary structures are developed continuously. For instance, Singh et al. (2014) presented their fabrication technique for a sintered aluminium evaporator of a Loop Heat Pipe. Santos et al. (2012) proposed an evaporator made of ceramic. Their experience helps in developing evaporators that will be more advanced in the future.

Besides developing new capillary structures with new techniques and new materials, a strong challenge is to determine the properties of existing capillary structures and to develop predictive tools that can be used in heat pipe models. The measurement of the permeability of a porous medium can be performed easily (Ameli et al., 2013; Hansen et al., 2015). However, the effective permeability of the capillary structure inside a heat pipe may be different from the bulk permeability of the medium because of the influence of the liquid-vapour interface.

The measure of the global porosity can be easily performed knowing the mass and the volume of the wick. This method was used by Deng et al. (2013) as an example. However, it does not give any information about the distribution of the porosity in the wick, which is important to know in some configurations like biporous wicks. The measurement of the effective pore radius is also complicated because the contact angle between the fluid and the wick affects its value. For instance, Singh et al. (2014) used the bubble point testing method, which 
enables to determine the largest pore radius whereas Becker et al. (Becker et al., 2011) characterised their wick by the measure of the smallest radius of curvature of the interface before the depriming of the wick. To characterise the pore size distribution, other methods need to be used, as the mercury injection or the imbibition (Dullien, 2012) but these methods remain challenging in practice.

From a thermal point of view, the determination of the equivalent thermal conductivity of the capillary structure is even more difficult. It can be performed with a flash method, for instance (Ababneh et al., 2014), but the measured value takes into account only conduction through the capillary structure and does not consider evaporation or condensation phenomena. More sophisticated set-ups have to be developed to take into account these phenomena (Iverson et al., 2007) but there is a lack of experimental data and studies in this field.

\subsection{Example of contribution of inverse methods}

When direct measurements cannot be performed, another approach consists in using inverse methods. This approach is illustrated in this section with a novel method proposed by Revil-Baudard and Lips (2015). The authors aimed to determine the capillary structure properties from measurements of the overall performance of a flat plate heat pipe under different inclination angles. The determination of the thermal properties was based on an analytical method that was directly inverted: the equivalent thermal conductivities of the capillary structure at the condenser and at the evaporator were thus the outputs of the inverse method, whereas the temperature measurements along the heat pipe were the inputs (figure 5). This technique enabled a direct comparison between the properties of the capillary structure of various heat pipes even if the global thermal resistances of the systems were different. It was the first step for the construction of an experimental equivalent thermal conductivity database for the development of predictive tools.

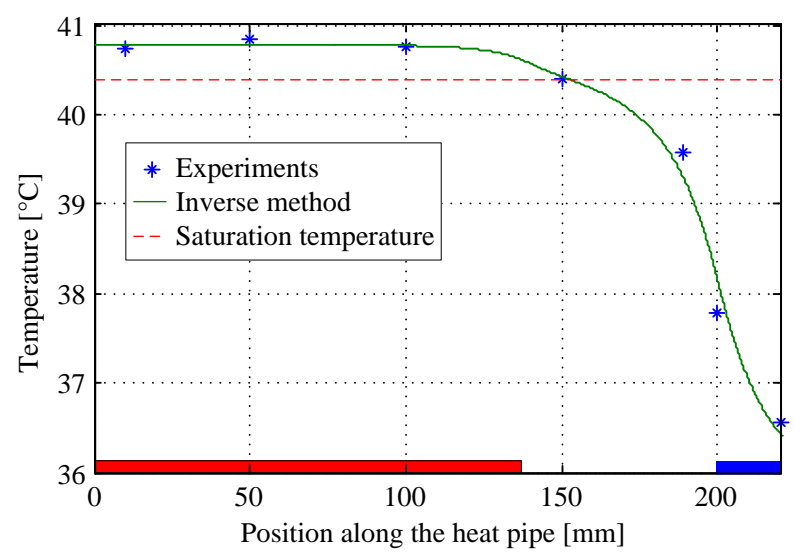

Figure 5 Example of comparison between an experimental temperature profile and the corresponding profile calculated by the inverse method for a flat plate heat pipe (Revil-Baudard \& Lips, 2015)

The determination of the hydrodynamic properties of the capillary structure, i.e. its effective permeability and its effective pore radius is more difficult, as no direct measurement can be performed in a non-transparent 
heat pipe. The method is based on the measurement of the capillary limit for different inclination angles. The capillary limit is reached when the sum of the gravitational and frictional pressure drops is equal to the maximum capillary pressure that the wick structure can sustain. It leads to a dry-out at the evaporator and thus to an increase of the thermal resistance of the heat pipe. When the heat pipe is tilted in unfavourable positions, the capillary limit decreases because of the effect of the gravitational pressure drop. The frictional pressure drop and the effective pore radius of the capillary structure can be estimated by assuming that the capillary pressure at the capillary limit is constant whatever the inclination angle (figure 6). This method has been successfully tested on a grooved flat plate heat pipe and validated by means of microscopy measurements. However, more studies are required to use this method with other capillary structures, as the assumption of a constant capillary pressure at the capillary limit of the heat pipe is not trivial.

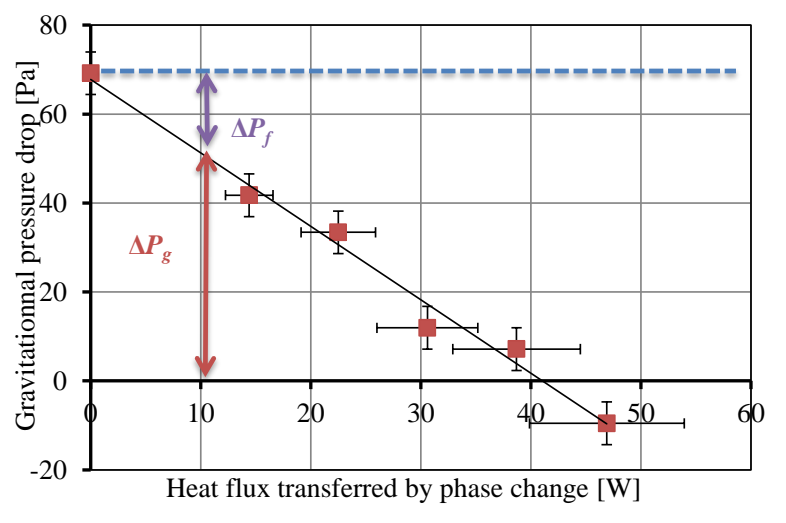

Figure 6 Example of evolution of the gravitational pressure drop as a function of the heat transfer rate transferred by phase change $\left(\mathrm{L}_{\text {evap }}=140 \mathrm{~mm}\right)($ Revil-Baudard \& Lips, 2015)

This example deals with flat heat pipes, but inverse methods can be used for a wide range of studies and are often the only way to determine accurately various parameters. For instance, Mehta and Khandekar (2014) used an inverse method to determine the heat transfer coefficient between the wall and a Taylor bubble train flow in a mini-channel of square cross-section $(5 \mathrm{~mm}$ x $5 \mathrm{~mm})$. They coupled experimental data from IR visualisation with a numerical model that takes into account the 3D conduction in the wall. The protocol for measuring the local heat transfer coefficient was far from being simple and they concluded that the major challenges were to get a sufficient spatial resolution to determine local temperature gradients and to minimise the conjugate heat transfer effect in the system. This effect depends strongly on the wall thickness, but also on the frequency and length of the bubbles in the flow.

As a conclusion, even if a large number of papers are devoted to the determination of the heat pipe performance and/or the capillary structure properties, there is often a need in understanding the phenomena that take place in the heat pipe itself, as the models often assume a given heat pipe behaviour, which is not always verified experimentally. 


\section{SCIENTIFIC ISSUES LINKED TO THE WORKING FLUID BEHAVIOUR}

\subsection{Towards a better understanding of the operating regimes and the fluid behaviour}

The performance of a heat pipe often depends on numerous parameters and specific studies focus on the understanding of the heat pipe behaviour itself. For conventional capillary heat pipes, the operating conditions are bounded by several limits that all lead to a dry-out at the evaporator. For thermosyphons, pulsating heat pipes and loop heat pipes, several operating regimes can be observed and recent progresses have been made in their characterisation. As an example, Miscevic et al. (2012) and Kaled et al. (2012) studied the flow regimes and the transient behaviour of a CPL, respectively. They concluded that the pseudo-periodicity of the system was affected by the fluid motion and had a direct influence on the pressure drops in the loop.

Operating regime is also of a great importance for PHPs. Karthikeyan et al. (2014) studied the self-sustained oscillations in a PHP by means of an infrared camera (figure 7). They characterised the different operating regimes and their impact on the heat pipe performance.
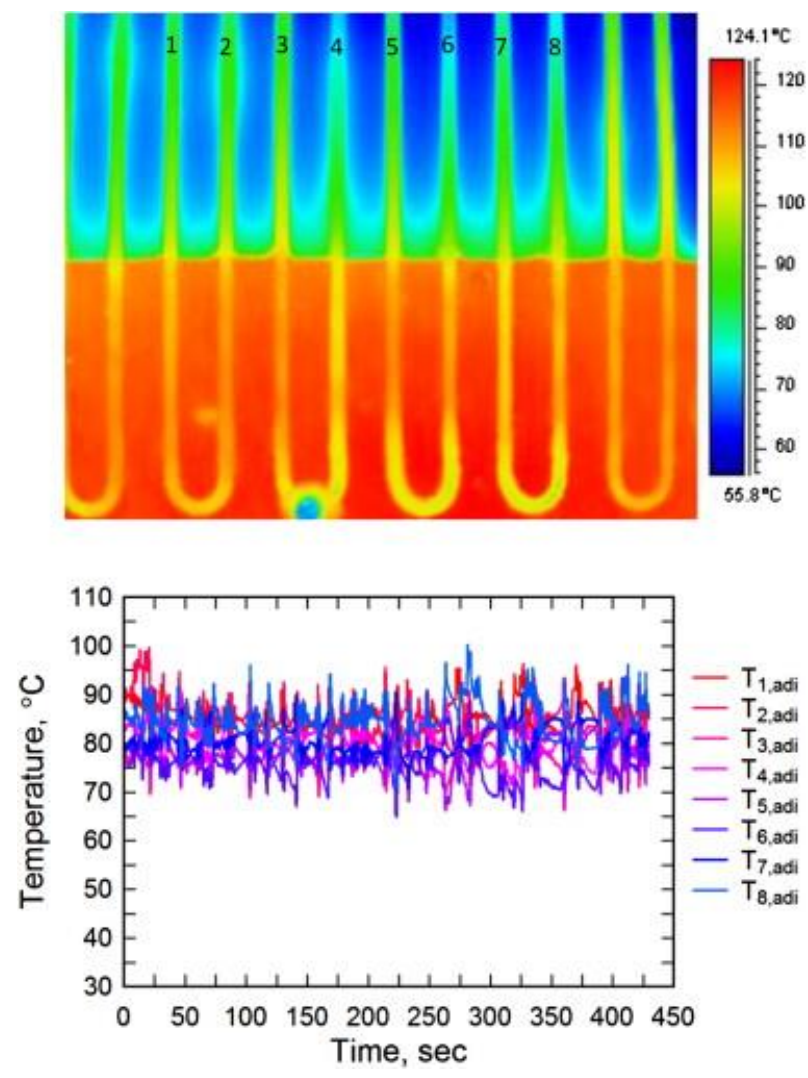

Figure 7 Experimental characterisation of the operating regimes of a PHP by means of a thermal camera (V. K. Karthikeyan et al., 2014)

Thermal measurements help to characterise the heat pipe behaviour, but it is often important to deal with the behaviour of the working fluid inside the capillary structure itself. Heat pipes are often studied as black boxes and thus no direct observation can be performed inside the system. For the last ten years, many research teams 
studied transparent heat pipes, which allow a better understanding of the physical phenomena that take place inside the system.

As an example, Lips et al. (2010; 2011) used a confocal microscope to measure the pressure drops of the liquid inside 1D and 2D capillary structures. These experimental results enabled the validation of the hydrodynamic models of the liquid flow in grooves. However, this technology cannot be used to visualise liquid/vapour interfaces in other capillary structures, like meshes or sintered wicks: the prediction of the pressure drops in this type of capillary structure remains an important challenge. The confocal microscopy was also successfully used for the measurement of the condensing film thickness in a silicon heat pipe (Lefèvre et al., 2010). Indeed, the geometry of the condensing film is of great importance in heat pipes, as it directly affects the thermal resistance of the condenser. The contribution of the confocal microscopy to the knowledge of flat heat pipe behaviour is discussed here as an example, but transparent systems were also widely used for the study of thermosyphons (Smith et al., 2014), pulsating heat pipes (Ji et al., 2013) and loop heat pipes (Xu et al., 2014).

In order to study the liquid-vapour interface shape in details, some studies focus on a sub-system of the heat pipe only. For instance, El Achkar et al. (2012) studied the condensation of n-pentane in a micro-channel that represents the condenser of a LHP. They measured the size and the frequency of the vapour bubbles during the condensation and quantified the distribution between sensible and latent heats of phase change. On the other hand, Mottet et al. (2015) developed a test bench dedicated to the study of partial dry-out in the evaporator of a LHP. A pseudo evaporator was designed and experimental results were compared to model predictions.

These examples of experimental works highlight the importance of the direct visualisation in these kinds of systems: the distribution of the liquid and vapour phases in the capillary structure of a heat pipe is far from being trivial and the numerical models are often limited by an imperfect understanding of the fluid behaviour. This lack of knowledge directly impacts the accuracy of the heat pipe design tools as the prediction of their thermal performance mainly depends on the liquid film thicknesses in the condenser and evaporator.

\subsection{Research on new fluids}

Besides research on the fluid behaviour inside the heat pipe, some studies are dedicated to new kinds of fluids themselves. The choice of the fluid is indeed of a great importance and it is not so trivial to choose an appropriate fluid for the appropriate heat pipe technology for a specific application. The fluid properties must show a good trade-off between high latent heat of vaporisation, surface tension and thermal conductivity and a low viscosity for the whole range of operating temperatures. A given operating temperature corresponds to a given operating pressure that the heat pipe must be able to withstand. The compatibility between the working fluid and the other materials must also be perfect. This problem currently limits the use of flexible and/or lightweight heat pipes because of the poor chemical stability of materials like plastics or polymer composites. 
An example of compatibility table proposed by Mishkinis et al. (2010) is presented on figure 8. This table shows that studies on fluid/material compatibilities can be contradictory and that more studies are required to get a complete knowledge of the possible interactions between the working fluids and the wick and structural materials.

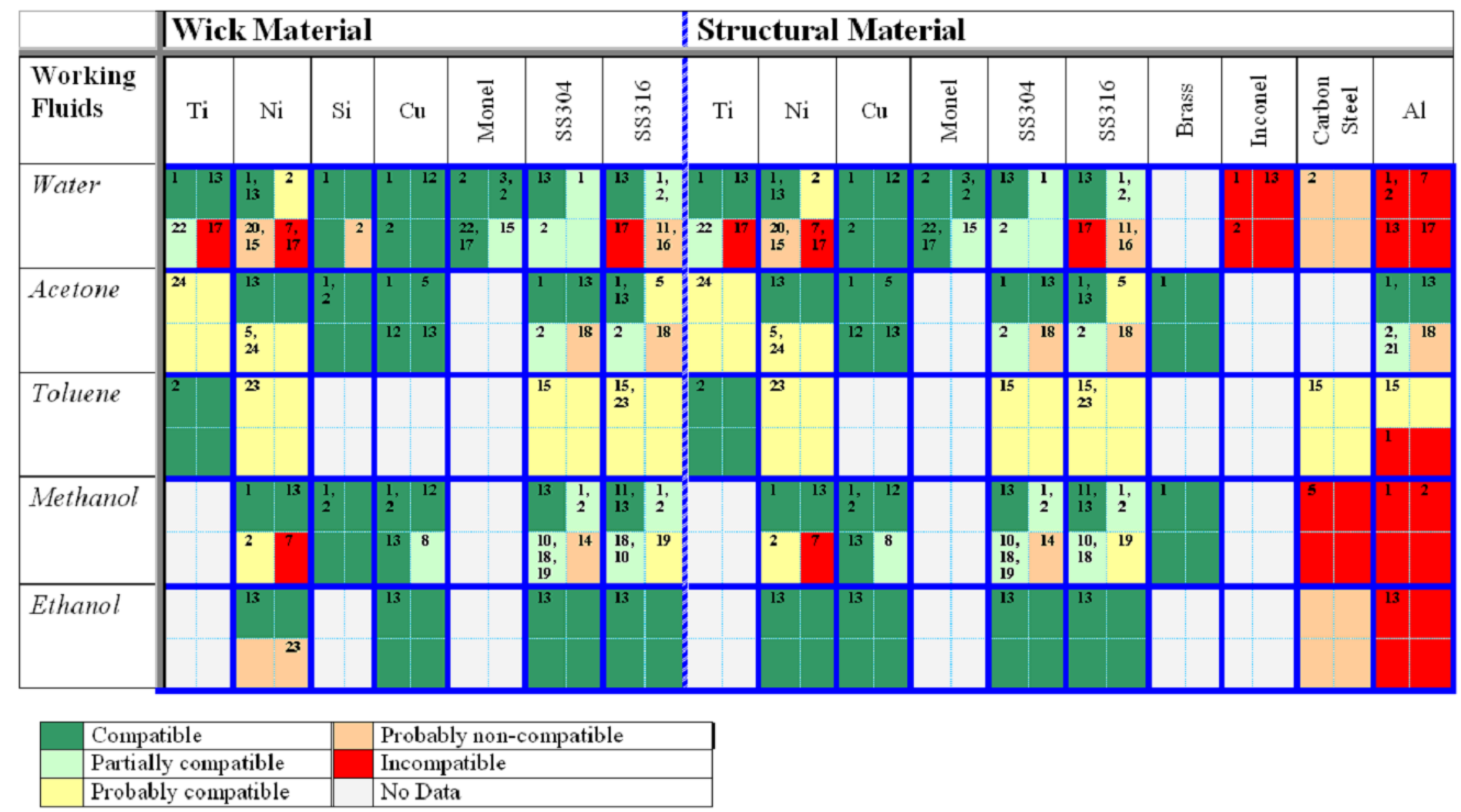

Figure 8 Compatibility table between the working fluids and the wick and structural materials (Mishkinis et al., 2010)

Other criteria, like toxicity for the humans and the environment must also be taken into account. As an example, water can be an appropriate working fluid for an operating temperature range from $50^{\circ} \mathrm{C}$ to $150^{\circ} \mathrm{C}$, but problems of low pressure and high pressure can occur out of this range. Moreover, freezing can also be a problem for heat pipes with certain kinds of capillary structures. Studies on new fluids are thus necessary.

For instance, MacGregor et al. (2013) proposed a comparison of different working fluid performances for thermosyphons in order to replace R134a, widely used, but subjected to a ban in the near future. Other authors also tested their prototypes with new refrigerants, as R1234ze, which was found to be an efficient working fluid for loop heat pipes (Yeo et al., 2014). For cryogenic applications, superfluid helium was also tested (Gully, 2015). In a general way, the definition of an efficient working fluid is still a subject of discussion. Since the initial approach of Chi (1976) to define a figure of merit for cylindrical grooved heat pipes, other figures of merit were proposed. For instance, Launay et al. (2010) proposed figures of merit for the working fluid in loop heat pipes, whereas Arab and Abbas (2014) proposed a model to predict the thermal performance of a trapezoidal grooved heat pipe when changing the working fluid. 
Besides new fluids themselves, contemporary heat pipe research is mainly focusing on two new fluid families: the self-rewetting fluids and the nano-fluids.

The self-rewetting fluids exhibit an increase of their surface tension when their temperature increases. They often consist of a dilute aqueous solution of alcohol: in a certain range of temperatures, a concentration gradient occurs at the evaporator and the Marangoni effect adds to the temperature effect and helps in draining the fluid from the condenser to the evaporator. Firstly studied for space applications (Savino et al., 2010), self-rewetting fluids have now been successfully tested in conventional heat pipes (Senthilkumar et al., 2012), thermosyphons (M. Karthikeyan et al., 2013) and even oscillating heat pipes (Hu et al., 2014). The self-rewetting fluids have proven their potential efficiency, but more studies are still required to precisely predict their behaviour.

A nanofluid consists in a liquid base in which nanometric size metallic/ non-metallic/ ceramic particles are incorporated, quite often with surfactants to ensure their stability. Depending on their material, the nanoparticles enable to get a working fluid with enhanced or tailor-made thermo-physical properties. In the last years, numerous studies on nanofluids in heat pipes have been published. Liu and Li (2012) performed a review of the dedicated studies and concluded that depending on the type of nanoparticles, their size and their concentration, nanofluids could significantly increase the heat pipe performances, both in terms of thermal resistance and of maximum heat removal capacity. The major effect of nanofluids seems to be the surface structuration of the evaporator, which affects the wettability of the wall, as well as the boiling phenomenon (Stutz et al., 2011). These conclusions are shared by other review articles recently published (Sureshkumar et al., 2013 ; Alawi et al., 2014). At present however, there are conflicting results and opinions on the efficacy of such fluids in heat pipe and thermosyphon systems. For instance, Khandekar et al. (2008) observed a decrease of the thermal performance of a PHP when nanofluids are used as working fluids. The nanoparticle clogging affected the boiling phenomenon and the authors tried to quantify the effects of the various mechanisms (figure 9). More focussed research is this area needs to be undertaken for clarity (Buschmann, 2013). The effect of the wall structuration on the heat transfer is further discussed in the section 5 of the present manuscript.
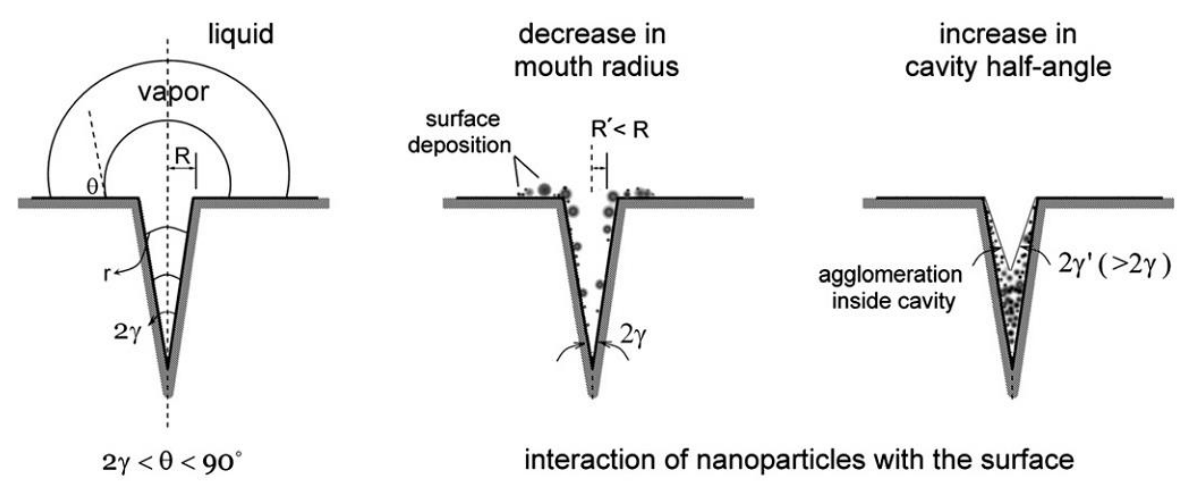

interaction of nanoparticles with the surface

Figure 9 Possible clogging of nanoparticles in a nucleating cavity (left) affecting mouth radius and cavity half-angle, and thus the boiling phenomenon (Khandekar et al., 2008). 
Figure 10 shows the number of publications dedicated to nanofluids in heat pipes according to the database of Web of Science ${ }^{\mathrm{TM}}$. The number of papers increased rapidly between 2006 and 2010, but has decreased since then. Finally, the studies on nanofluids can be considered as studies on liquid-vapour phase change heat transfer on nanostructured surface. However, the change in structural morphology of the wall depends on numerous parameters, as it is time-dependent and involves many aging phenomena of the nanofluid (aggregation, deposition, etc.). As a conclusion, if the positive effect of nanofluids on heat pipe performance is well admitted, they mainly affect the heat transfer coefficient during the phase change heat transfer and the pressure drops in the capillary structure. No phenomenon specific to heat pipes was observed, which could explain the decrease of the number of articles dedicated to nanofluids in heat pipes since 2010.

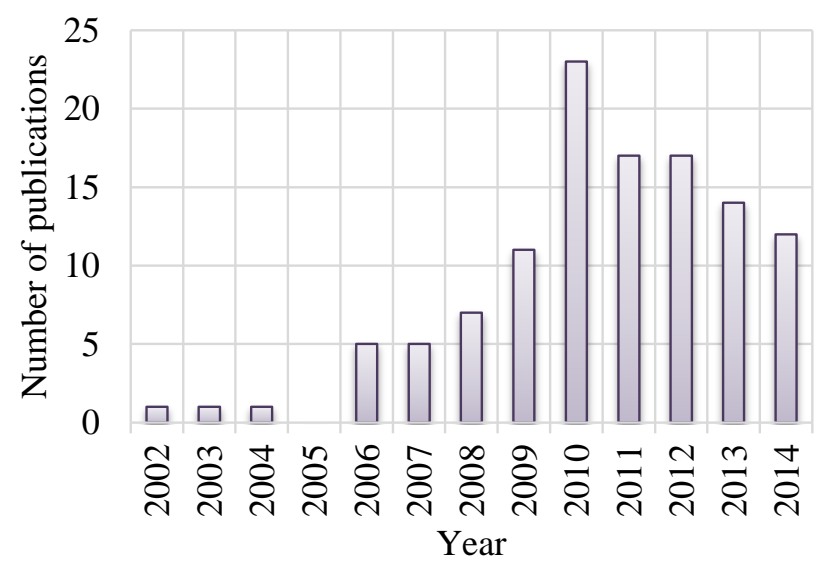

Figure 10 Number of publications dedicated to nanofluids in heat pipes according to the database of Web of Science $^{\mathrm{TM}}$

\section{STUDIES AIMING TO PREDICT THE PHASE CHANGE HEAT TRANSFER IN THIN FILMS}

Yet, wall structuration (should it be nanostructuration or microstructuration) can still be viewed as a promising track for the improvement of the efficiency of heat pipes. Heat pipes are certainly one applicative motivation of many research works on the boiling or condensation heat transfer enhancement using structured surfaces. Regarding condensation, the objective is quite often to promote dropwise condensation by modifying the fluid wettability: making a surface (super-)hydrophobic facilitates the roll-off of the droplets, which improves the overall condensation heat transfer. (Super-)hydrophobic surfaces are generally obtained by acting on the surface chemical or physical characteristics to decrease the surface energy, or by acting on the surface roughness (Bisetto et al., 2014). Different processes of chemical coating of the solid substrate with a low surface-energy substance are currently being developed and evaluated, as explained by Sikarwar et al. (2011).

Regarding boiling (i.e. for an application to thermosiphons), heat transfer enhancement techniques have been studied for decades, from the emergence of extended surfaces in the 1970ies-1990ies to the development, like for condensation, of microstructured surfaces and more recently nanostructured surfaces. Extended surfaces 
are manufactured based on standard machining and metal processing. Microstructured surfaces can be obtained by means of porous coating, or by deformation of extended surfaces (e.g. low fins compression, fin bending and cutting, etc.), as described Poniewski and Thome (2008). Nanostructuration relies on chemical processes (oxidation, etching, etc.) or nanoelectromechanical systems (NEMS). Enhanced surfaces are usually used for two distinct purposes: either to increase the critical heat flux, or to increase the heat transfer coefficient.

Beyond a simple increase in heat transfer area, extended surfaces can be employed to optimise the distribution of active nucleation sites or to favour the liquid flow around the heated wall. In addition, when reducing the size of the structures that form the extension down to micrometer or nanometer size, additional phenomena can come into play, as reviewed by Kim et al. (2015) among many other reviews on the subject of interest. For instance, while nucleation takes place within the pores of a porous coating, liquid can be fed to the nucleation site by means of capillary pumping. Micro- or nanoscale geometric effects (size, but also liquid flow distribution) can also favour the bubble initiation, growth or detachment, while the micro- or nanostructure will modify the fluid wetting characteristics, which will ultimately affect both the heat transfer coefficient and CHF. As an example, the effect of the nanostructuration with a $\mathrm{Fe}_{2} \mathrm{O}_{3}$ nanofluid on the boiling curve of a $100 \mu \mathrm{m}$ platinum wire is presented on figure 11 (Stutz et al., 2011): depending on the nano-particle coating duration (and thus on the shape of the nanostructuration), the heat transfer coefficient can be increased or decreased but the CHF is always increased by this nano-particle coating.

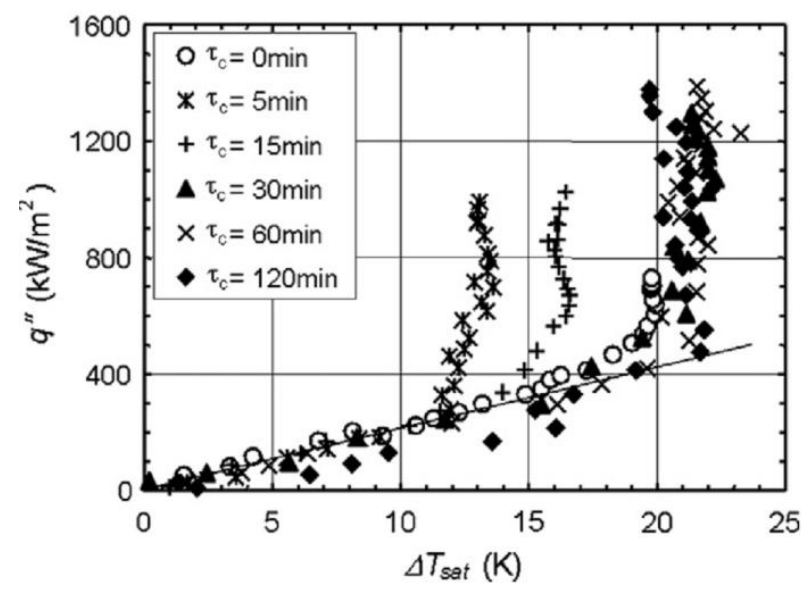

Figure 11 Example of the effect of the nanostructuration of the wall on the boiling curve obtained with $\gamma$ $\mathrm{Fe}_{2} \mathrm{O}_{3}$ nanoparticle on a $100 \mu \mathrm{m}$ platinum wire. $\tau_{\mathrm{c}}$ is the nano-particle coating duration with pure water (Stutz et al., 2011).

Lastly, there are also many attempts to take the benefit of the new possibilities offered by micro- and nanotechnologies to improve the wick structures that come into play in all the capillary heat pipes (Ranjan et al., 2011) where capillary evaporation occurs, especially LHPs. As a matter of fact, while the performance of these heat pipes is usually limited by both the ability of the wick to ensure capillary pumping and by its thermal resistance, micro- or (probably better) nanoscale objects (e.g. nanowires, nanotubes, etc.) should help improve 
both wicks characteristics as leading to smaller menisci (i.e. increased capillary pumping), as they usually have a greater thermal conductivity, and as they allow for an enhancement of evaporation (Plawsky et al., 2014).

However, the difficulty in predicting the thermal performance of a heat pipe actually lies in the predominance of heat transfer through very thin liquid films. Numerous studies aim to determine the heat transfer coefficients during condensation or evaporation, but the models fail to reproduce the measurements, even for simple geometries as grooves (Lips et al, 2010). Studies dealing with micro-heat pipes (and thus with very simple geometries) are often limited to theoretical considerations and there is a lack of experimental validation (Liu \& Chen, 2013). For PHPs, Khandekar et al. (2010) pointed that too many fundamental phenomena still need to be understood to achieve a complete model because of the pulsating and/or oscillating character of the Taylor bubble flow. Experimental set-ups were developed to study the evaporation and condensation phenomena in capillary tubes. For instance, Chauris et al. (2015) studied the evaporation of the thin film deposited by a moving meniscus. They highlighted the phenomena involved in the process and quantified the impact of each phenomenon on the global heat transfer by comparing their experimental results with a numerical model. They concluded that during the transit of a meniscus, most of the energy is transferred through the thin liquid film deposited by the meniscus, but the impact of the meniscus itself is not negligible.

Other recent studies focus on heat transfer in thin films, but with no direct application to heat pipes. As an example, Srinivasan et al. (2015) performed an experimental study that aims to understand the mechanisms occurring during the evaporation of an isolated liquid slug. They focused particularly on the drainage of the thin liquid film and found a good agreement with the Taylor's law predictions. Kunkelmann et al. (2012) studied experimentally and theoretically the effect of the three-phase contact line velocity on the heat transfer. They concluded that the heat transfer in the contact line zone mainly depends on the micro-layer evaporation and on the transient conduction in the wall. At the scale of the liquid thin film, the properties of the wall are indeed found to be not negligible and the coupling of the phenomena is complex. 
To highlight this complexity, a study performed by Rao et al. (2015) and dedicated to the understanding of a single-branch pulsating heat pipe is taken here as an example. This study illustrated the coupling of thermal and hydrodynamic phenomena, which could lead to self-sustained oscillations. The experimental set-up of the authors consisted of a single vertical and transparent capillary tube, closed on one side, and connected to a reservoir on the other side. Two transparent water heat exchangers, acting as an evaporator and a condenser, were located along the heat pipe. This experimental set-up did not intend to represent a real pulsating heat pipe but it could be viewed as a model to study some fundamental physical phenomena while avoiding the hydraulic interactions between the different branches of a real pulsating heat pipe. Depending on the temperatures of the reservoir, the evaporator and the condenser, self-sustained oscillations of the meniscus were indeed observed. The authors simultaneously measured the meniscus position, the triple contact line position, the vapour pressure and the vapour temperature. They described the four stage cycle associated to the meniscus oscillation and highlighted the main phenomena involved in the process (figure 12).

The observed cycle was a result of a balance between the pressure of the reservoir, the frictional pressure drop, the variation of pressure due to the compression and expansion phenomena and the variation of pressure due to the change of vapour mass, resulting from condensation and evaporation of the fluid. The four stage shape was due to the difference of time scale between the hydrodynamic phenomena and the phase change phenomena. The authors showed that the vapour was always superheated, which is in accordance with the conclusions of Gully et al. (2013). It enabled them to determine the instantaneous mass of vapour and to estimate by a thermal model the rate of evaporation and condensation in various zones of the liquid-vapour interface during a cycle. Condensation occurred mainly on the liquid film and evaporation occurred on the liquid film but it is particularly significant close to the triple contact line. For both evaporation and condensation, the phase change rate was maximum when the meniscus was at its second bottom-most position.

Even if the conclusions of this study cannot be directly used to explain the overall principle of a real pulsating heat pipe because of its too simplified behaviour, this study is a good example of the complexity of the balance between thermal and hydrodynamic phenomena that can occur in this kind of systems. This is particularly important in a pulsating heat pipe, but also in all kinds of heat pipes where evaporation through thin liquid films occurs. In the case of a pulsating heat pipe, no complete model is able to predict their behaviour, but the progress in the understanding of the phenomena contributes to more realistic models. 

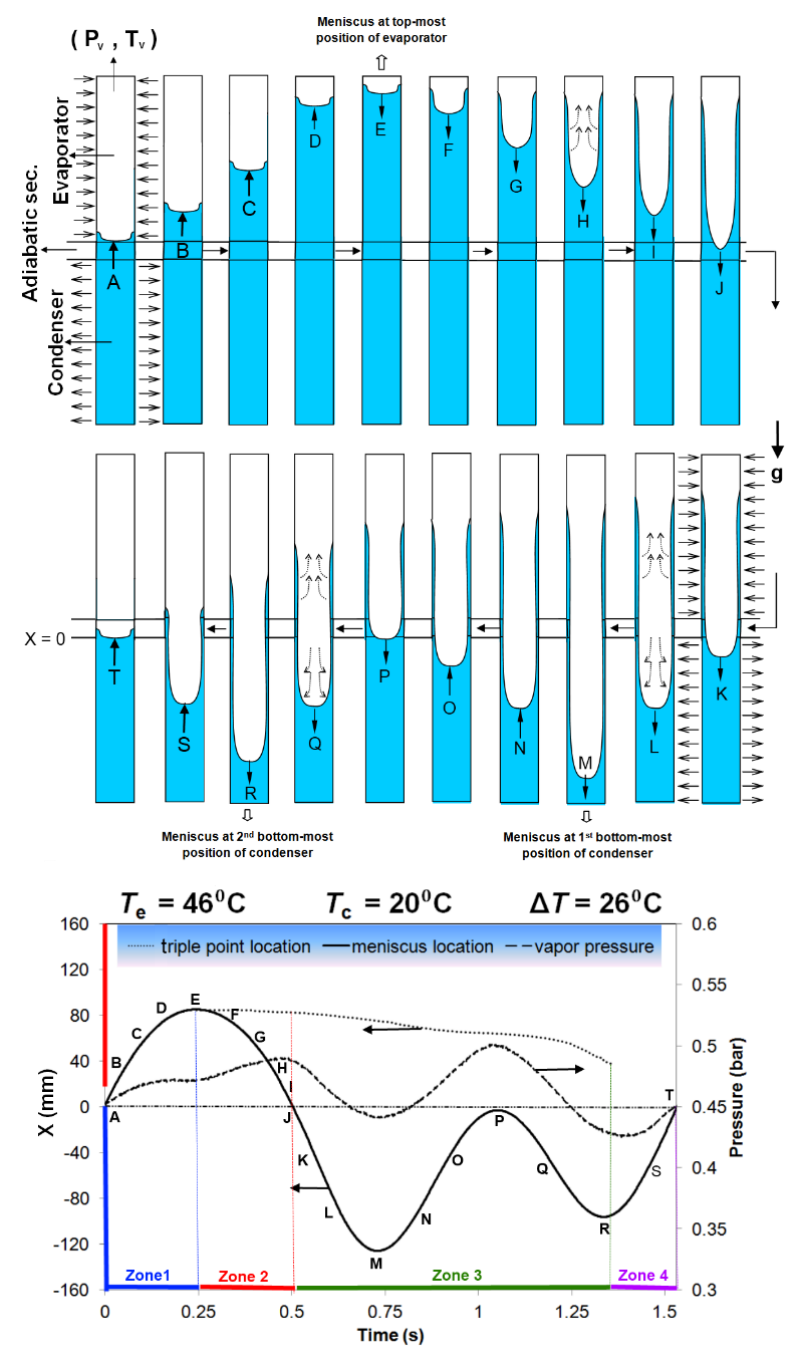

Figure 12 Description of the four zone cycle and the associated phenomena (Rao et al., 2015)

\section{THE DEVELOPMENT OF NEW HEAT PIPE MODELS}

During the past few years, heat pipe models have indeed been improved. Both analytical and numerical models were proposed at the scale either of a single phenomenon or of the system. The goal of the present article is not to precisely describe the complete set of equations on which the models published in the literature are based, but rather to give a brief overview of the panel of models that are still under development today.

Concerning conventional heat pipes (thermosyphons and capillary heat pipes), two types of studies were published: the progress in CFD modelling enabled the development of 3D thermal and hydrodynamic models (Jung-Chang Wang, 2012), but in parallel, analytical models are proposed (Lips \& Lefèvre, 2014). The first ones enable a better integration of the heat pipes in a more complex system, whereas the second ones give simple and accurate engineering tools for the design of the heat pipes themselves. Some other specific studies aim to determine the wick properties by means of detailed thermal and hydrodynamic models at the pore scale (Ranjan et al., 2012). These three different approaches are very complementary and each of them leads to a better understanding of the phenomena involved in each type of conventional heat pipe. 
Several studies are devoted to the modelling of loop heat pipes. Siedel et al. (2015b) proposed a comprehensive review of the steady-state modelling works. They highlighted the high number of models available and noted that most of them are numerical. The same authors proposed, in another article, a complete analytical model, requiring a low computational time compared to numerical ones (Siedel et al., 2015a). These models are able to reproduce the experiments, but their limit lies in the lack of knowledge of the wick properties (permeability and effective thermal conductivity), of the accommodation coefficient of the working fluid and of the thermal contact resistance between the wall and the wick structure. The presence, or absence, of a vapour zone at the contact between the porous medium and the heat source is also a source of discussion. Mottet et al. (2015) developed a 3D model of a wicked LHP evaporator. They used a mesoscale approach with a pore network model. Their model enabled to highlight phenomena that a $2 \mathrm{D}$ model could not reproduce and the authors made the distinction between different regimes governed by different phenomena. The best regime is found to be when a two-phase liquid-vapor zone forms just at the contact of the evaporator casing. Their simulation enables to guide the design of new wicks for LHPs.

At the scale of the system, transient models of LHPs have been proposed. For instance, Kaled et al. (2012) proposed a model classically based on the energy, mass and momentum balances for the evaporator-reservoir, the condenser and the transport lines. They concluded that the fluid motion participates in the pseudo-periodic behaviour of the system. In parallel, Nishikawara et al. (2013) proposed a transient model that correctly predicts the experimental data, despite the presence of an overshoot temperature when the heat load changes, which is not observed experimentally.

An important part of the modelling works published in the last few years are devoted to pulsating heat pipes. On one side, the increasing number of experimental databases enables the development of empirical correlations (Qu \& Wang, 2013). On the other side, some 3D CFD models are proposed (Lin et al., 2013) and phenomenological models are implemented. They show a good ability to reproduce the chaotic behaviour of PHPs (Nikolayev, 2011). In all cases, these models still have to be improved in order to take into account all physical phenomena, especially at the scale of the thin liquid film and the triple contact line. Detailed models already exist to understand these phenomena, but their experimental validation remains challenging (Nikolayev, 2010).

\section{SUMMARY AND CONCLUSIONS}

This brief review of recent studies focused on heat pipes enables to highlight the main approaches used by the research teams to increase the understanding of the various types of systems. Both experimental and theoretical works are proposed and the scale of interest of the studies varies from the system size itself to the scale of the very thin liquid film present in the evaporation and condensation zones.

During the past five years, some significant advances have been achieved: 
- The understanding of evaporation and condensation phenomena on a capillary scale has been improved, mainly thanks to new systems of visualisation and instrumentation.

- New fluids and new materials have been successfully tested and enabled to increase the performance of heat pipes.

- Major progresses in the understanding of LHPs have now enabled to develop this technology at an industrial scale. The models are now able to predict the experiments satisfactorily even if improvements could still be achieved in the prediction of transient behaviour and thermal resistances involved in the systems. From a technological point of view, new geometries and types of capillary structure have also been proposed (bi-porous wick, multi-layer wick, ceramic wick ...). A new challenge is now the miniaturisation of the systems.

- The more impressive advances are probably related to the PHPs. Five years ago, even the main phenomena were not well identified. Models are now almost able to reflect their chaotic behaviour and reliable predictive tools can be expected in the coming few years.

However, several scientific questions still need to be answered:

- The predictive tools strongly depend on the capillary structure properties and on the heat transfer coefficient during condensation and evaporation. Limited progress has been realised in developing satisfactory models or correlations, even for simple geometries.

- Several phenomena still have to be better understood to be correctly taken into account in the models. Boiling in the capillary structure of a flat heat pipe and coalescence and break-up of liquid slugs and vapour plugs in pulsating heat pipes are only two examples.

- The evaporation and condensation processes implying thin liquid films are not yet fully understood, and especially the influence of the wall properties on these phenomena. If the case of fully wetting fluids is supported by some theoretical backgrounds, partial wetting, which is present in real engineering systems, still needs to be understood.

To answer these questions, more studies will be required. First of all, experimental studies with visualisation are essential because of the need to understand the coupling between the different phenomena involved in these systems. The lack of experimental data is even more acute for the phenomena that act at the micro-scale. For instance, without the knowledge of the accommodation coefficient, the thermal models of phase change heat transfer at the triple contact line cannot be validated. The real mechanisms leading to the onset of nucleate boiling are also not yet fully understood and this strongly limits the predictability of the numerical models as they almost always need to be fitted with experimental data. Besides this, there is a lack of reliable convective condensation models at low flow rates, able to predict the heat transfer coefficients in small and bended tubes such as the LHP condensers. Another challenge will be to couple these microscale models to the system scale models. This difficulty comes partially from the fact that the physical, topological and chemical properties of 
the materials are often poorly known. To answer this issue, more interactions should be created between the heat pipe research community and the material science research community.

One can also expect that the progresses in other research fields will bring new tools enabling to improve the current systems. For instance, the progress in high frequency micro-electronics opens the way for active control of heat pipes and the continuous development of new materials awake hopes of real flexible and lightweight heat pipes if the current problems of fluid/material compatibility on plastic heat pipes are solved. Anyway, one can conclude that the study of heat pipes will remain a challenging and exciting topic at least for the next couple of decades.

\section{REFERENCES}

Ababneh, M. T., Gerner, F. M., Chamarthy, P., Bock, P. de, Chauhan, S., Deng, T., 2014, "Thermal-fluid modeling for high thermal conductivity heat pipe thermal ground planes," Journal of Thermophysics and Heat Transfer, 28(2), 270-278.

Alawi, O. A., Sidik, N. A. C., Mohammed, H. A., Syahrullail, S., 2014, "Fluid flow and heat transfer characteristics of nanofluids in heat pipes: A review," International Communications in Heat and Mass Transfer, 56, 50-62.

Ameli, M., Agnew, B., Leung, P. S., Ng, B., Sutcliffe, C. J., Singh, J., McGlen, R., 2013, “A novel method for manufacturing sintered aluminium heat pipes (SAHP)," Applied Thermal Engineering, 52(2), 498-504.

Arab, M., Abbas, A., 2014, "A model-based approach for analysis of working fluids in heat pipes," Applied Thermal Engineering, 73(1), 751-763.

Asfia, J. F., Cai, Q., Chen, C.-L., 2014, May 13, "Multi-layer wick in loop heat pipe," http://www.google.com/patents/US8720530

Becker, S., Vershinin, S., Sartre, V., Laurien, E., Bonjour, J., Maydanik, Y. F., 2011, "Steady state operation of a copper-water LHP with a flat-oval evaporator," Applied Thermal Engineering, 31(5), 686-695. Bisetto, A., Torresin, D., Tiwari, M. K., Del Col, D., Poulikakos, D., 2014, "Dropwise condensation on superhydrophobic nanostructured surfaces: literature review and experimental analysis," In Journal of Physics: Conference Series (Vol. 501, p. 12028).

Bonjour, J., Lefevre, F., Sartre, V., Siedel, B., 2013, November 28, "Improved device for closed-loop heat transport," http://www.google.com/patents/WO2013174856A1

Buschmann M., 2013, "Nanofluids in thermosyphons and heat pipes: Overview of recent experiments and modelling approaches", International Journal of Thermal Sciences, 72, 1-17.

Chauris, N., Ayel, V., Bertin, Y., Romestant, C., 2015, "Evaporation of a liquid film deposited on a capillary heated tube: Experimental analysis by infrared thermography of its thermal footprint," International Journal of Heat and Mass Transfer, 86, 492-507.

Chi, S. W., 1976, Heat pipe theory and practice: a sourcebook. Hemisphere Pub. Corp.

Deng, D., Liang, D., Tang, Y., Peng, J., Han, X., Pan, M., 2013, "Evaluation of capillary performance of sintered porous wicks for loop heat pipe," Experimental Thermal and Fluid Science, 50, 1-9.

Dullien, F. A., 2012, Porous media: fluid transport and pore structure. Academic press 
El Achkar, G., Lavieille, P., Miscevic, M., 2012, "Loop heat pipe and capillary pumped loop design: About heat transfer in the isolated bubbles zone of condensers," Applied Thermal Engineering, 33-34, 253-257.

Fried, S. S., Maydanik, Y. F., Kozhin, V. A., 2013, Liquid cooled condensers for loop heat pipe like enclosure cooling. Google Patents http://www.google.com/patents/US8422218

Gully, P., 2015, “Superfluid Helium Heat Pipe,” Physics Procedia, 67, 625-630.

Gully, P., Bonnet, F., Nikolayev, V., Luchier, N., Tran, T. Q., 2013, "Evaluation of the vapour thermodynamic state in PHP," In 17th International Heat Pipe Conference. Kanpur, India

Hansen, G., Naess, E., Kristjansson, K., 2015, "Sintered nickel powder wicks for flat vertical heat pipes," Energies, 8(4), 2337-2357.

Hu, Y., Liu, T., Li, X., Wang, S., 2014, "Heat transfer enhancement of micro oscillating heat pipes with selfrewetting fluid," International Journal of Heat and Mass Transfer, 70, 496-503.

Iverson, B. D., Davis, T. W., Garimella, S. V., North, M. T., Kang, S. S., 2007, "Heat and mass transport in heat pipe wick structures," Journal of Thermophysics and Heat Transfer, 21(2), 392-404.

Ji, Y., Liu, G., Ma, H., Li, G., Sun, Y., 2013, “An experimental investigation of heat transfer performance in a polydimethylsiloxane (PDMS) oscillating heat pipe," Applied Thermal Engineering, 61(2), 690-697.

Kaled, A., Dutour, S., Platel, V., Lachassagne, L., Ayel, V., 2012, “A theoretical analysis of the transient behavior of a CPL for terrestrial application," In 16th International Heat Pipe Conference. Lyon, France

Kim, D. E., Yu, D. I., Jerng, D. W., Kim, M. H., Ahn, H. S., 2015, "Review of boiling heat transfer enhancement on micro/nanostructured surfaces," Experimental Thermal and Fluid Science, 66, 173-196.

Karthikeyan, M., Vaidyanathan, S., Sivaraman, B., 2013, "Heat transfer analysis of two-phase closed thermosyphon using aqueous solution of n-butanol," International Journal of Engineering and Technology, 3(6), 661-667.

Karthikeyan, V. K., Khandekar, S., Pillai, B. C., Sharma, P. K., 2014, "Infrared thermography of a pulsating heat pipe: Flow regimes and multiple steady states," Applied Thermal Engineering, 62(2), 470-480.

Khandekar, S., Panigrahi, P. K., Lefèvre, F., Bonjour, J., 2010, “Local hydrodynamics of flow in a pulsating heat pipe: a review," Frontiers in heat pipes, 1(2), 023001-1; 023001-20.

Khandekar, S., Joshi, Y., Mehta, B., 2008, “Thermal Performance of closed two-phase thermosyphon using nanofluids", International Journal of Thermal Sciences, 47(6), 659-667.

Kim, N., Kim, S., 2014, "Self-convectional three-dimensional integrated circuit cooling system using micro flat heat pipe for portable devices," Heat Transfer Engineering, 35(10), 924-932.

Kunkelmann, C., Ibrahem, K., Schweizer, N., Herbert, S., Stephan, P., Gambaryan-Roisman, T., 2012, "The effect of three-phase contact line speed on local evaporative heat transfer: Experimental and numerical investigations," International Journal of Heat and Mass Transfer, 55(7-8), 1896-1904.

Lachassagne, L., Ayel, V., Romestant, C., Bertin, Y., 2012, "Experimental study of capillary pumped loop for integrated power in gravity field," Applied Thermal Engineering, 35, 166-176.

Lachassagne, L., Bertin, Y., Ayel, V., Romestant, C., 2013, "Steady-state modeling of Capillary Pumped Loop in gravity field," International Journal of Thermal Sciences, 64, 62-80.

Larsen, P. O., von Ins, M., 2010, "The rate of growth in scientific publication and the decline in coverage provided by Science Citation Index," Scientometrics, 84(3), 575-603.

Launay, S., Sartre, V., Bonjour, J., 2010, "Selection criteria for fluidic and geometrical parameters of a LHP based on analytical approach.," In 15th International Heat Pipe Conference. Clemson, USA 
Lefèvre, F., Rullière, R., Lips, S., Bonjour, J., 2010, "Confocal microscopy for capillary film measurements in a flat plate heat pipe," Journal of Heat Transfer, 132(3), 031502.

Lin, Z., Wang, S., Shirakashi, R., Winston Zhang, L., 2013, "Simulation of a miniature oscillating heat pipe in bottom heating mode using CFD with unsteady modeling," International Journal of Heat and Mass Transfer, 57(2), 642-656.

Lips, S., Lefèvre, F., 2014, “A general analytical model for the design of conventional heat pipes," International Journal of Heat and Mass Transfer, 72, 288-298.

Lips, S., Lefevre, F., Bonjour, J., 2010, "Investigation of evaporation and condensation processes specific to grooved flat heat pipes.," Frontiers in heat pipes, 1(2), 023001-1;023001-8.

Lips, S., Lefèvre, F., Bonjour, J., 2010, “Thermohydraulic study of a flat plate heat pipe by means of confocal microscopy: application to a 2D capillary structure," Journal of Heat Transfer, 132, 019008.

Lips, S., Lefèvre, F., Bonjour, J., 2011, "Physical mechanisms involved in grooved flat heat pipes: Experimental and numerical analyses," International Journal of Thermal Sciences, 50(7), 1243-1252.

Liu, Z.-H., Li, Y.-Y., 2012, “A new frontier of nanofluid research-Application of nanofluids in heat pipes," International Journal of Heat and Mass Transfer, 55(23), 6786-6797.

Liu, X., Chen, Y., 2013, “Transient thermal performance analysis of micro heat pipes," Applied Thermal Engineering, 58(1-2), 585-593.

MacGregor, R. W., Kew, P. A., Reay, D. A., 2013, "Investigation of low global warming potential working fluids for a closed two-phase thermosyphon," Applied Thermal Engineering, 51(1-2), 917-925.

Mameli, M., Araneo, L., Filippeschi, S., Marelli, L., Testa, R., Marengo, M., 2014, "Thermal response of a closed loop pulsating heat pipe under a varying gravity force," International Journal of Thermal Sciences, 80, $11-22$.

Maydanik, Y. F., Chernysheva, M. A., Pastukhov, V. G., 2014, "Review: Loop heat pipes with flat evaporators," Applied Thermal Engineering, 67(1-2), 294-307.

McNaught, C., Lam, P., 2010, “Using Wordle as a supplementary research tool," The Qualitative Report, 15(3), 630-643.

Mehta, B., Khandekar, S., 2014, "Measurement of local heat transfer coefficient during gas-liquid Taylor bubble train flow by infra-red thermography," International Journal of Heat and Fluid Flow, 45, 41-52.

Miscevic, M., El Achkar, G., Lavieille, P., Kaled, A., Dutour, S., 2012, “About flow regime and heat transfer in low diameter condenser of LHP and CPL," In 16th International Heat Pipe Conference (Vol. 029). Lyon, France

Mishkinis, D., Prado, P., Sanz, R., Torres, A., 2010, "Development of LHP for Intermediate Temperature Range," In 15th International Heat Pipe Conference (15th IHPC), Clemson, Etats-Unis

Mottet, L., Coquard, T., Prat, M., 2015, “Three dimensional liquid and vapour distribution in the wick of capillary evaporators," International Journal of Heat and Mass Transfer, 83, 636-651.

Nikolayev, V. S., 2010, "Dynamics of the triple contact line on a nonisothermal heater at partial wetting," Physics of Fluids, 22(8), 082105.

Nikolayev, V. S., 2011, “A dynamic film model of the pulsating heat pipe,” Journal of HeatTransfer, 133(8), 081504.

Nishikawara, M., Nagano, H., Kaya, T., 2013, "Transient thermo-fluid modeling of loop heat pipes and experimental validation," Journal of Thermophysics and Heat Transfer, 27(4), 641-647. 
Plawsky, J. L., Fedorov, A. G., Garimella, S. V., Ma, H. B., Maroo, S. C., Chen, L., Nam, Y., 2014, "Nano- and Microstructures for Thin-Film Evaporation-A Review," Nanoscale and Microscale Thermophysical Engineering, 18(3), 251-269.

Poniewski, M. E., Thome, J. R., 2008, Nucleate boiling on micro-structured surfaces. Heat Transfer Research, Inc. (HTRI), College Station

Qu, J., Wang, Q., 2013, “Experimental study on the thermal performance of vertical closed-loop oscillating heat pipes and correlation modeling," Applied Energy, 112, 1154-1160.

Ranjan, R., Garimella, S. V., Murthy, J. Y., Yazawa, K., 2011, “Assessment of nanostructured capillary wicks for passive two-phase heat transport," Nanoscale and Microscale Thermophysical Engineering, 15(3), $179-194$.

Ranjan, R., Patel, A., Garimella, S. V., Murthy, J. Y., 2012, "Wicking and thermal characteristics of micropillared structures for use in passive heat spreaders," International Journal of Heat and Mass Transfer, 55(4), 586-596.

Rao, M., Lefèvre, F., Khandekar, S., Bonjour, J., 2015, "Heat and mass transfer mechanisms of a self-sustained thermally driven oscillating liquid-vapour meniscus," International Journal of Heat and Mass Transfer, 86, $519-530$.

Reay, D., McGlen, R., Kew, P., 2013, Heat Pipes: Theory, Design and Applications (6th ed.). Amsterdam u.a.: Butterworth-Heinemann

Revil-Baudard, L., Lips, S., 2015, “A non-invasive method for thermal and hydrodynamic characterisation of flat plate heat pipes," In 9th International conference on Boiling and Condensation Heat Transfer. Boulder, Colorado

Riffat, S., Ma, X., 2007, "Recent developments in heat pipe technology and applications: a review," International Journal of Low-Carbon Technologies, 2(2), 162-177.

Santos, P. H. D., Bazzo, E., Oliveira, A. A. M., 2012, "Thermal performance and capillary limit of a ceramic wick applied to LHP and CPL," Applied Thermal Engineering, 41, 92-103.

Savino, R., Di Paola, R., Cecere, A., Fortezza, R., 2010, “Self-rewetting heat transfer fluids and nanobrines for space heat pipes," Acta Astronautica, 67(9-10), 1030-1037.

Senthilkumar, R., Vaidyanathan, S., Sivaraman, B., 2012, "Comparative study on heat pipe performance using aqueous solutions of alcohols," Heat and Mass Transfer, 48(12), 2033-2040.

Siedel, B., Sartre, V., Lefèvre, F., 2015a, "Complete analytical model of a loop heat pipe with a flat evaporator," International Journal of Thermal Sciences, 89, 372-386.

Siedel, B., Sartre, V., Lefèvre, F., 2015b, "Literature review: Steady-state modelling of loop heat pipes," Applied Thermal Engineering, 75, 709-723.

Sikarwar, B. S., Battoo, N. K., Khandekar, S., Muralidhar, K., 2011, "Dropwise condensation underneath chemically textured surfaces: simulation and experiments," Journal of Heat Transfer, 133(2), 21501.

Singh, R., Nguyen, T., Mochizuki, M., 2014, "Capillary evaporator development and qualification for loop heat pipes," Applied Thermal Engineering, 63(1), 406-418.

Smith, K., Kempers, R., Robinson, A. J., Siedel, S., 2014, "Flow visualisation in a transparent thermosyphon: influence of internal pressure," In 15th International Heat Transfer Conference. Kyoto, Japan

Srimuang, W., Amatachaya, P., 2012, "A review of the applications of heat pipe heat exchangers for heat recovery," Renewable and Sustainable Energy Reviews, 16(6), 4303-4315.

Srinivasan, V., Marty-Jourjon, V., Khandekar, S., Lefèvre, F., Bonjour, J., 2015, "Evaporation of an isolated liquid plug moving inside a capillary tube," International Journal of Heat and Mass Transfer, 89, 176-185. 
Stutz, B., Morceli, C. H. S., da Silva, M. de F., Cioulachtjian, S., Bonjour, J., 2011, "Influence of nanoparticle surface coating on pool boiling," Experimental Thermal and Fluid Science, 35(7), 1239-1249.

Sureshkumar, R., Mohideen, S. T., Nethaji, N., 2013, "Heat transfer characteristics of nanofluids in heat pipes: A review," Renewable and Sustainable Energy Reviews, 20, 397-410.

Wang, J.-C., 2012, “3-D numerical and experimental models for flat and embedded heat pipes applied in highend VGA card cooling system," International Communications in Heat and Mass Transfer, 39(9), 1360-1366.

Wang, Z., Zhang, X., Li, Z., Luo, M., 2015, “Analysis on energy efficiency of an integrated heat pipe system in data centers," Applied Thermal Engineering, 90, 937-944.

Xu, J., Zhang, L., Xu, H., Zhong, J., Xuan, J., 2014, “Experimental investigation and visual observation of loop heat pipes with two-layer composite wicks," International Journal of Heat and Mass Transfer, 72, 378-387.

Yeo, J., Yamashita, S., Hayashida, M., Koyama, S., 2014, “A loop thermosyphon type cooling system for high heat flux," Journal of Electronics Cooling and Thermal Control, 4(04), 128-137.

Zhang, X., Shen, J., Xu, P., Zhao, X., Xu, Y., 2014a, "Socio-economic performance of a novel solar photovoltaic/loop-heat-pipe heat pump water heating system in three different climatic regions," Applied Energy, 135, 20-34.

Zhang, X., Zhao, X., Shen, J., Xu, J., Yu, X., 2014b, "Dynamic performance of a novel solar photovoltaic/loopheat-pipe heat pump system," Applied Energy, 114, 335-352. 